\title{
Effect of maternal positioning during cardiopulmonary resuscitation: a systematic review and meta-analyses
}

Naosuke Enomoto', Tomoyuki Yamashita ${ }^{2}$, Marie Furuta ${ }^{3}$, Hiroaki Tanaka ${ }^{\text {* }}$, Edmond S. W. Ng ${ }^{4}$,

Shigetaka Matsunaga ${ }^{5}$, Atsushi Sakurai ${ }^{6}$ and on behalf of the Japan Resuscitation Council Maternal task force

\begin{abstract}
Background: Although rare, cardiac arrest during pregnancy is the leading cause of maternal death. Recently, its incidence has been increasing worldwide because more pregnant women have risk factors. The provision of early, high-quality cardiopulmonary resuscitation (CPR) plays a major role in the increased likelihood of survival; therefore, it is important for clinicians to know how to manage it. Due to the aortocaval compression caused by the gravid uterus, clinical guidelines often emphasise the importance of maternal positioning during CPR, but there has been little evidence regarding which position is most effective.
\end{abstract}

Methods: We searched the Cochrane Central Register of Controlled Trials, MEDLINE, Embase, and OpenGrey (updated on April 3, 2021). We included clinical trials and observational studies with reported outcomes related to successful resuscitations.

Results: We included eight studies from the 1,490 screened. The eight studies were simulation-based, crossover trials that examine the quality of chest compressions. No data were available about the survival rates of mothers or foetuses/neonates. The meta-analyses showed that resuscitation of pregnant women in the $27^{\circ}-30^{\circ}$ left-lateral tilt position resulted in lower quality chest compressions. The difference is an 19\% and $9 \%$ reduction in correct compression depth rate and correct hand position rate, respectively, compared with resuscitations in the supine position. Inexperienced clinicians find it difficult to perform chest compressions in the left-lateral tilt position.

Conclusions: Given that manual left uterine displacement allows the patient to remain supine, the resuscitation of women in the supine position using manual left uterine displacement should continue to be supported. Further research is needed to fill knowledge gaps regarding the effects of maternal positioning on clinical outcomes, such as survival rates following maternal cardiac arrest.

Keywords: Maternal cardiac arrest, Cardiopulmonary resuscitation, Pregnant women, Patient positioning

*Correspondence: h_tanaka@med.miyazaki-u.ac.jp

${ }^{1}$ Department of Obstetrics and Gynaecology, Graduate School

of Medicine, Mie University / Mie University Hospital, 2-174 Edobashi, Tsu,

Mie 514-8507, Japan

Full list of author information is available at the end of the article

\section{Introduction}

Cardiac arrest during pregnancy is rare but life-threatening and involves the lives of two patients: the mother and the fetus [1]. Nationwide population-based studies from the United States, Canada, the United Kingdom and the Netherlands indicate the incidence of maternal cardiac arrest during pregnancy is approximately 1 in 12,000 to 1 in 36,000 [2-5]. The incidence of maternal 
cardiac arrest and related maternal mortality have increased in several countries over the past 30 years [3, $6,7]$. This increase could be explained partially by more women with risk factors (rising maternal age, obesity and preexisting chronic medical conditions) becoming pregnant $[7,8]$. Common causes of maternal cardiac arrest and mortality include anaesthesia complications, bleeding, cardiovascular disease, embolism, uterine atony and hypertension/preeclampsia/eclampsia [6, 9, 10]. Previous studies have suggested that cardiac arrest in pregnant women is more responsive to cardiopulmonary resuscitation (CPR) compared to cardiac arrest in the general population since pregnant women are typically young [11-13].

The rate of maternal survival to hospital discharge for in-hospital maternal cardiac arrest is estimated to be as high as 59\% [3, 4], whereas the corresponding figure for maternal cardiac arrest occurring in out-of-hospital settings is much lower, at around 17\% [14]. The provision of early, high-quality CPR plays a significant role in increasing the likelihood of survival [15]. Although the resuscitation of a pregnant woman is similar to the standard resuscitation of adults, the physiological changes that occur during pregnancy impose additional clinical challenges $[6,15,16]$. Aortocaval compression occurs beginning around 20 weeks of gestation, when the growth of the uteroplacental unit compresses the aorta, inferior vena cava or both in the supine position [17]. Such compression can reduce cardiac output by as much as 30 to $40 \%$ [18]. During CPR, manual chest compressions could produce approximately $30 \%$ of the normal cardiac output for the nonpregnant situation [19]. Aortocaval compression in late pregnancy further reduces cardiac output to around $10 \%$ of the nonpregnant cardiac output $[20,21]$.

Clinical guidelines [22-27] recommend relief of aortocaval compression during maternal resuscitation. However, there is no consensus on the best strategy to relieve aortocaval compression during maternal resuscitation. Thus, the latest Royal College of Obstetricians and Gynaecologists guidelines on 'maternal collapse in pregnancy and the puerperium' recommended future researchers investigate the effectiveness of CPR with manual uterine displacement versus maternal tilt [20], both of which are considered beneficial in relieving aortocaval compression during chest compressions. A Cochrane systematic review on maternal position during caesarean section for preventing maternal and neonatal complications has been published [17], but the result was based on nonarrest pregnant women, and in light of the quality of chest compression, some strategies that could be effective in relieving aortocaval compression for nonarrest pregnant patients might not be the best option for pregnant women in cardiac arrest.
No current or planned systematic reviews regarding the effects of maternal positioning or strategies were identified in a search of the Cochrane Library, International Prospective Register of Systematic Reviews (PROSPERO) or the Joanna Briggs Institute. Therefore, our systematic review aimed to synthesise the evidence to evaluate the effect of maternal positioning and other strategies during resuscitation to determine which is most effective in improving outcomes following maternal cardiac arrest. Our findings will contribute to evidencebased decision-making for clinicians and provide a basis for the formation of national and international guidelines on the resuscitation of pregnant women.

\section{Materials and methods}

Our review was registered in PROSPERO (CRD42020208177) and conducted in accordance with Preferred Reporting Items for Systematic Reviews and Meta-Analyses (PRISMA) guidelines [28].

\section{Search strategy}

We searched the Cochrane Central Register of Controlled Trials (CENTRAL), MEDLINE, Embase and OpenGrey databases for relevant studies on 16 November 2019, and we updated them on 3 April 2021. We did not restrict the publication year. We also checked the reference lists of all included studies and relevant existing systematic reviews for additional studies. We used subject headings in combination with key words. We devised three sets of search terms: (i) population of interest (pregnant women), (ii) health condition of interest (cardiac arrest) and (iii) intervention (or exposure) evaluated (Table 1).

\section{Inclusion and exclusion criteria}

The study population included pregnant women who experienced cardiac arrest. We made no restrictions regarding maternal age, care settings or nationality. Regarding the intervention, we included studies that examined the effect of maternal positioning or methods to relieve aortocaval compression during CPR. We also included any type of study (randomised control trials [RCTs], nonrandomised clinical trials and observational studies). Because of the rarity of cardiac arrest during pregnancy, we included simulation-based studies using patient mannequins. We excluded reviews and commentaries as well as studies without English language abstracts (Table 2).

\section{Outcomes of interest}

The primary outcomes of interest included the survival rate of mothers or fetuses/neonates with favourable neurologic outcomes and the return of spontaneous circulation following maternal cardiac arrest. The secondary 
Table 1 Search strategy (Medline OvidSP) 1946 to April 2021

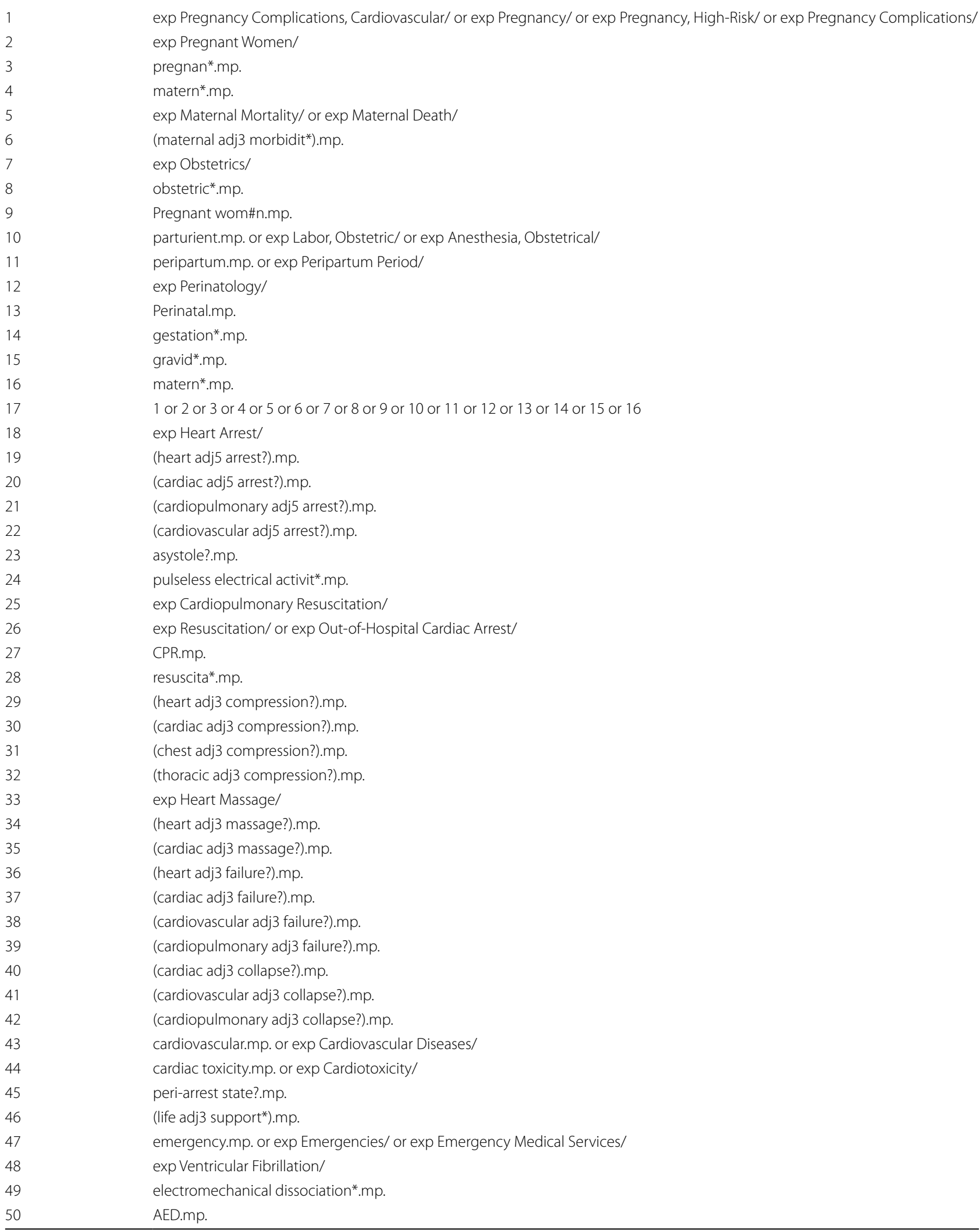


Table 1 (continued)

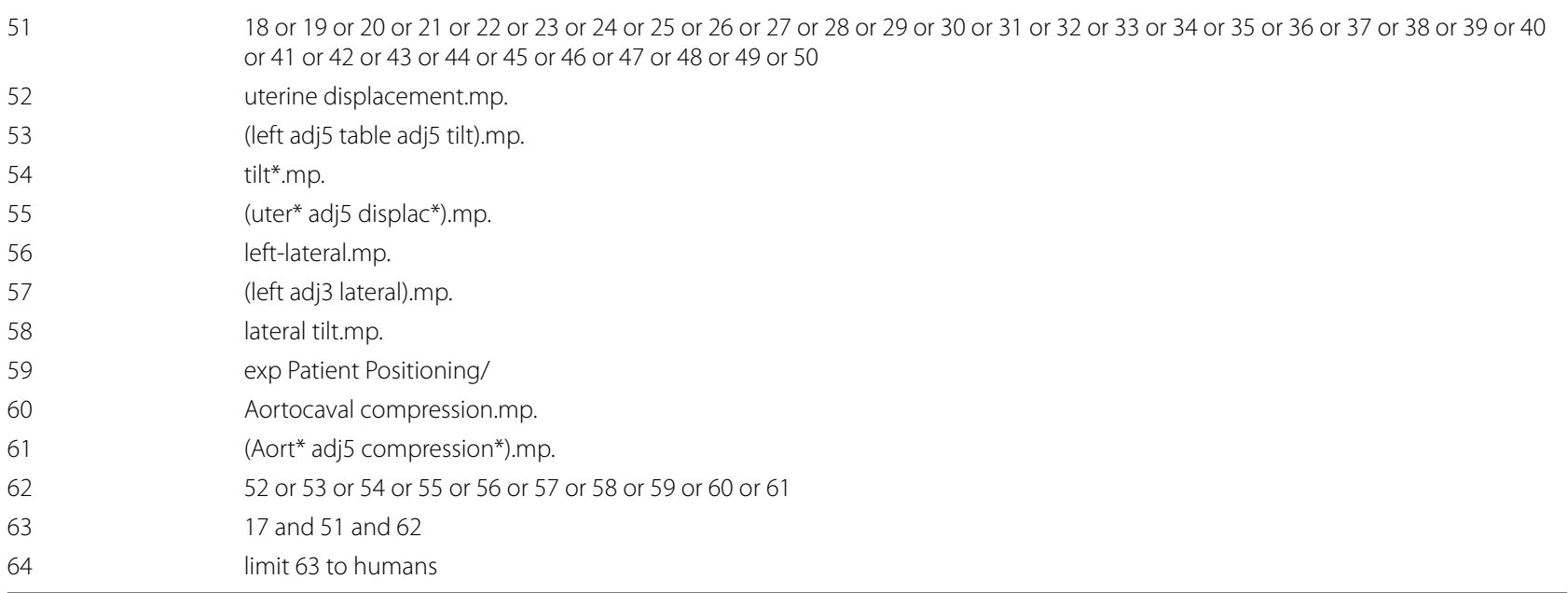

Table 2 Inclusion and exclusion criteria

\begin{tabular}{|c|c|c|}
\hline & Inclusion criteria & Exclusion criteria \\
\hline Population & - Pregnant women who have experienced cardiac arrest in any settings/countries & - None \\
\hline Intervention & $\begin{array}{l}\text { - Any maternal positioning during CPR } \\
\text { - Any methods to relieve aortocaval compression during CPR }\end{array}$ & - None \\
\hline Comparators & $\begin{array}{l}\text { - Studies with a comparison (or crossover comparison /any control group) to an } \\
\text { intervention group }\end{array}$ & - Studies with no comparison (control) group \\
\hline \multirow[t]{2}{*}{ Outcomes } & $\begin{array}{l}\text { - Maternal outcomes: } \\
\text { - Return of spontaneous circulation following maternal cardiac arrest } \\
\text { - Survival to hospital discharge } \\
\text { - Survival with favourable neurologic outcome } \\
\text { - Any adverse event } \\
\text { - Foetal or neonatal outcomes: } \\
\text { - Survival to hospital discharge } \\
\text { - Survival with favourable neurologic outcome } \\
\text { - Any adverse event } \\
\text { - Quality of CPR (e.g. quality of chest compression, quality of ventilation) }\end{array}$ & - Outcomes with no clinical relevance \\
\hline & $\begin{array}{l}\text { - Experimental studies (RCTs, quasi-RCTs, cross-over trials, etc.) with relevant primary } \\
\text { data }\end{array}$ & $\begin{array}{l}\text { - Qualitative studies } \\
\text { - Animal studies }\end{array}$ \\
\hline Study design & $\begin{array}{l}\text { - Observational studies (cohort, case-control, cross-sectional studies, etc.) with relevant } \\
\text { primary data } \\
\text { - Simulation-based studies }\end{array}$ & \\
\hline Language & $\begin{array}{l}\text { - Studies written in English } \\
\text { - Studies written in a language other than English that contain an abstract written in } \\
\text { English }\end{array}$ & - Studies without English abstract \\
\hline Publication & - Published and grey literature & - None \\
\hline Published year & - No restriction made & - None \\
\hline
\end{tabular}

outcomes of interest were the quality of CPR and any adverse events.

\section{Study selection}

We imported identified studies into Covidence, a webbased tool for systematic reviews. Two review authors (NE and TY) independently screened the studies for relevance based on titles and abstracts; they then screened based on full texts. We resolved any discrepancies via discussions with the review team until we reached a consensus.

\section{Data extraction and risk of bias assessment}

Using data extraction forms designed specifically for this review, two review authors (NE and MF) extracted data from the included studies. We contacted the 
authors of original studies to obtain missing information and unpublished data. Two review authors (MF and NE) independently assessed the risk of bias in the included studies using a revised Cochrane risk-of-bias tool (RoB2) developed specifically for crossover trials [29] because all studies included in this review applied a crossover design.

\section{Data synthesis and analysis}

Findings from nonrandomised crossover studies are presented narratively. Whenever sufficient data were available from RCTs to estimate the effect size of the intervention, we conducted meta-analyses using Cochrane's Review Manager (RevMan) version 5.3 [30]. We calculated the weighted mean difference and 95\% confidence interval (CI) for continuous outcomes. We performed the random effects meta-analyses, because we assumed that the impact of the maternal positioning during cardiopulmonary resuscitation varied from study to study [31]. We assessed clinical heterogeneity (e.g. variability in the interventions such as chest compression on different surfaces; the floor or on the bed) as well as methodological heterogeneity (e.g. variability in study design such as RCTs or nonrandomised studies) within each comparison. Where meta-analyses were performed, we assessed statistical heterogeneity with $\mathrm{tau}^{2}$ in addition to visual inspection of the forest plots [32]. We assessed heterogeneity using tau ${ }^{2}$, rather than $I^{2}$, as tau ${ }^{2}$ is the appropriate measure for indicating the presence of clinically relevant heterogeneity while $I^{2}$ may be misleading as it depends on the sample size of studies [33]. Furthermore, $I^{2}$ is not an absolute measure of heterogeneity [34, $35]$. We conducted subgroup analyses based on the clinical heterogeneity (chest compression delivery surfaces). If there was a concern to the robustness of the result caused by missing outcome data, sensitivity analysis would have been performed, by comparing results from different methods of dealing with missing data (e.g. available case analysis, imputed case analysis) [36, 37]

\section{Overall quality of evidence}

We used the Grading of Recommendations Assessment, Development and Evaluation (GRADE) approach [38] to assess the body of evidence for all the identified outcomes. We assigned one of four levels - high, moderate, low or very low - to each outcome by considering five domains, including the within-study risk of bias, inconsistency, indirectness, imprecision and publication bias [39]. If sufficient studies had been available $(>=10)$, then we would have constructed funnel plots to assess publication bias.

\section{Results}

\section{Search results}

The databases we searched identified 1,836 articles, including 346 duplicates. We screened a total of 1,490 titles and abstracts and selected 79 articles for full-text evaluation. We identified no additional articles from the reference lists of the included studies or review articles, and of the 79 articles that underwent full-text evaluation, we excluded 71 for the reasons stated in the PRISMA flowchart (Figure 1). A total of eight studies met the inclusion criteria, including six crossover RCTs [40-45] and two nonrandomised crossover studies [46, 47].

\section{Characteristics of included studies}

An overview of included studies is presented in Table 3. All the available studies used mannequins, and none involved living subjects. One crossover RCT [43] examined the effect of manual left uterine displacement in the supine position and compared the results to those in the left-lateral tilt position. Four crossover RCTs [40-42, 44] and one nonrandomised crossover study [46] compared the quality of CPR on a mannequin lying supine (manual left uterine displacement) with that of the leftlateral tilt position. One crossover RCT examined the optimal methods for producing lateral tilt [45], and one nonrandomised crossover study [47] examined the effect of chest compression at various angles between $0^{\circ}$ and $90^{\circ}$ of inclination. All participants in the included studies were health professionals and performed two or more sequential interventions.

\section{Risk of bias assessment}

Bias due to randomisation: Of the randomised crossover trials included in this review [40-45], none except one [45] reported the processes used to generate the random allocation sequence and/or allocation concealment. Bias due to deviations from intended interventions: Given the nature of the interventions, participants (rescuers) in all studies were aware of their assigned intervention (e.g. chest compression in the supine or lateral tilting positions) during each period of the trial. Four studies [40, 41, 44, 45] ensured a washout period to minimise the carryover effect (after 2 minutes of chest compressions in the first assigned position, the participants rested for 10 minutes to minimise rescuer fatigue), whereas no information was available to assess the carryover effect in the remaining studies [42, 43, 46, 47]. Bias due to missing outcome data: There were no missing outcomes [40-44, 46, 47], or the proportion of missing outcomes was small [45]. Bias due to outcome measurement: The outcomes were assessed using the PC SkillReporting software system, which was connected to the patient mannequin (Laerdal Resusci 


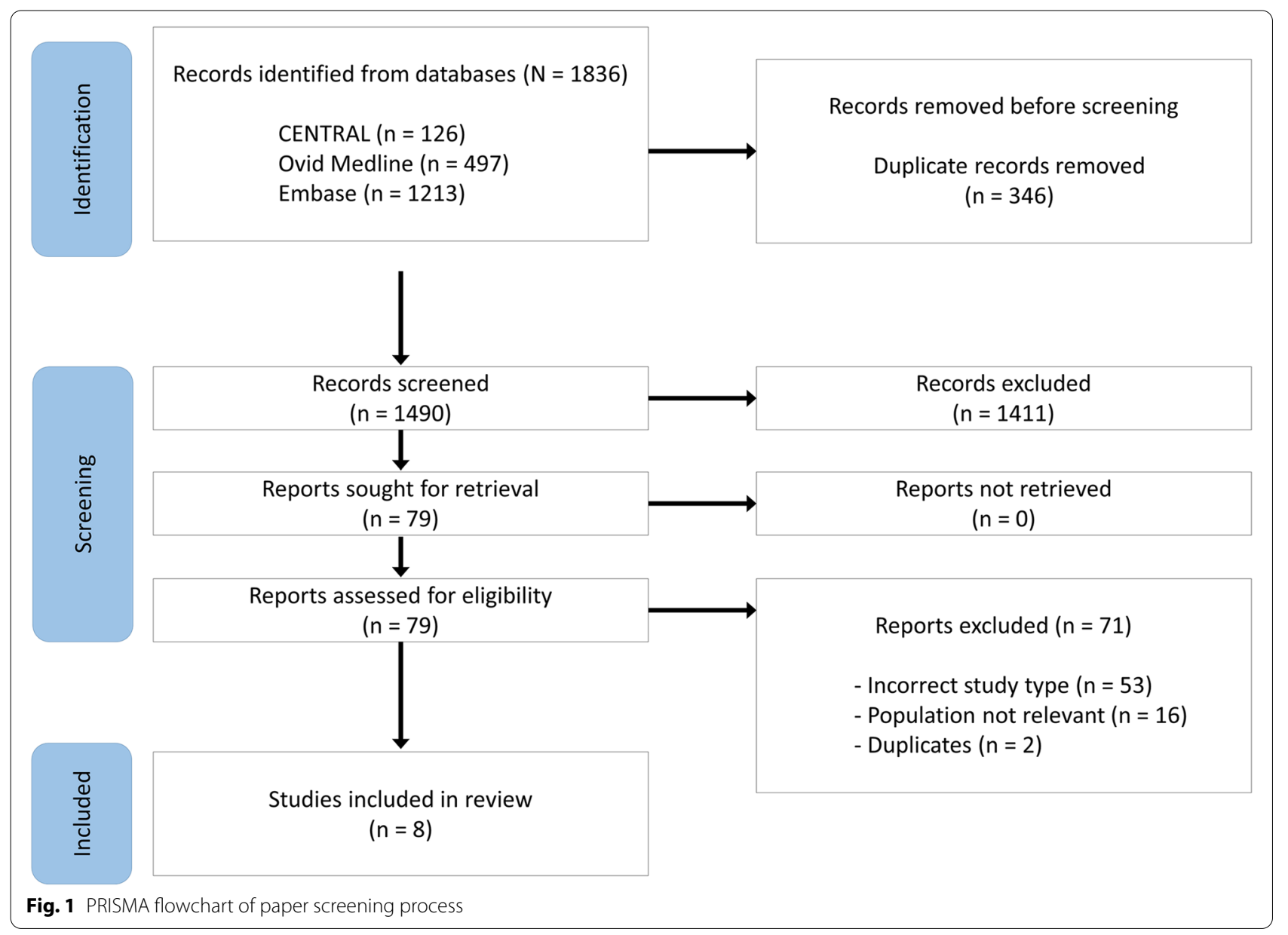

Anne ${ }^{\circledR}$ ) in all the included studies [40-46] except one [47]. Where the participants could not see the monitor screen displaying the outcomes during the chest compressions, the risk of bias was considered low [41, 44]; however, where information regarding blinding of the outcomes was not provided, the risk of bias was rated as of some concern by taking into account the possibility that knowing the outcomes altered the participants' performance [40, 42, 43, 45-47]. Bias due to selection of the reported result: No studies provided a trial protocol. Overall: Six RCTs [40-45] were rated as having some concern for risk bias, whereas the two nonrandomised crossover studies $[46,47]$ were considered of high risk for bias because at least one domain had a high risk of bias (Table 4).

\section{Intervention effectiveness}

\section{Maternal and foetal (or neonatal) outcomes}

Because all the studies included in this review were conducted on mannequins, no data regarding maternal or foetal/neonatal outcomes were available for our analysis.

\section{Quality of CPR and subjective stability/difficulty of chest compression}

All eight studies included in this review provided data regarding the quality of the CPR, and some provided data on subjective stability or difficulty (or ease) of chest compression (Table 5).

Comparison 1: Left lateral tilt position vs. manual left uterine displacement Quality of chest compression

Based on one crossover RCT [43] involving 20 health professionals, there was no statistically significant difference in the quality of chest compressions as measured with compression rates, compression depth, correct compression depth $(>50 \mathrm{~mm})$ rates and correct recoil rates between the manual left uterine displacement in the supine position and the left lateral tilt position produced by a firm-rubber wedge. The results were consistent both on the floor and on the bed. The mean compression rates observed ranged from $114.5 / \mathrm{min}$ to $118.5 / \mathrm{min}$ and were within the range of adequate compression rates recommended by clinical guidelines. However, insufficient 


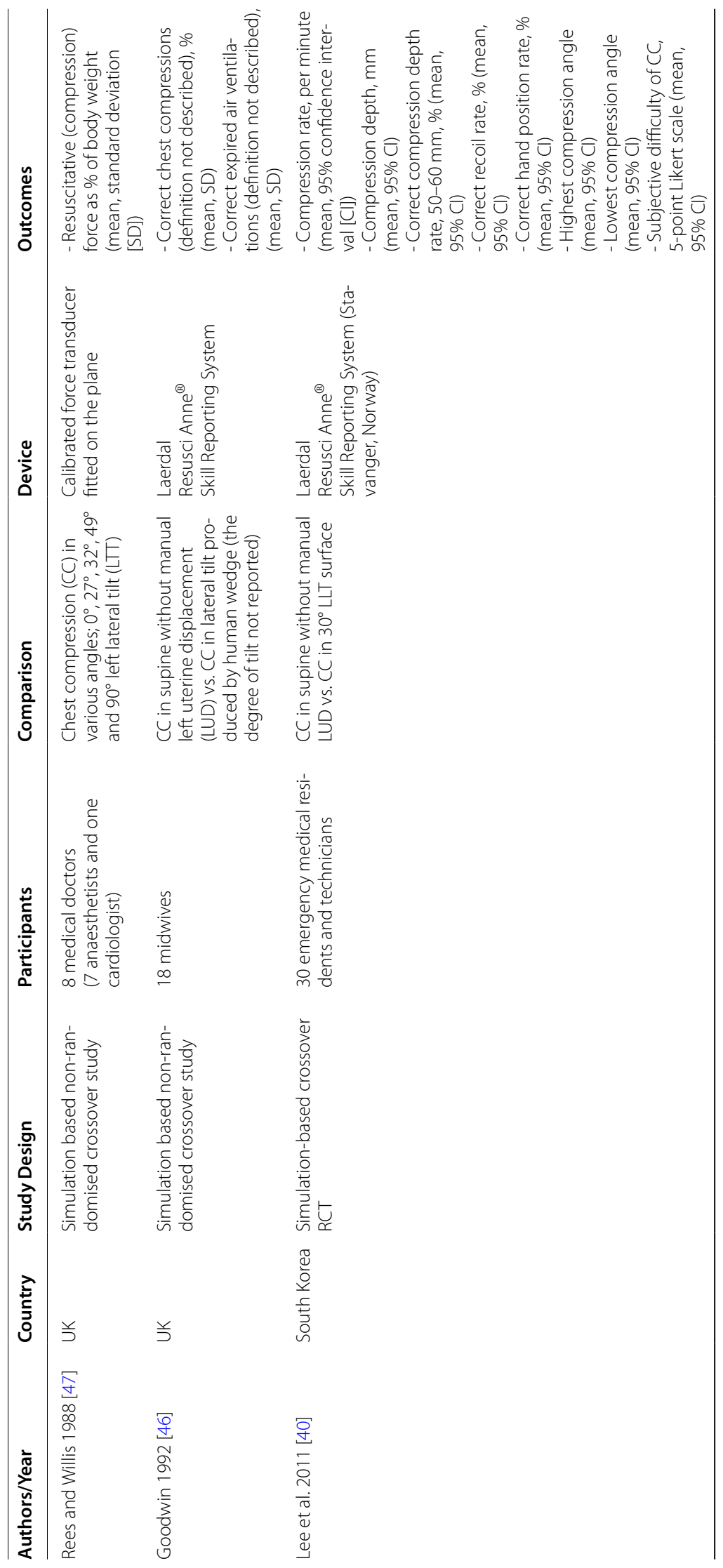




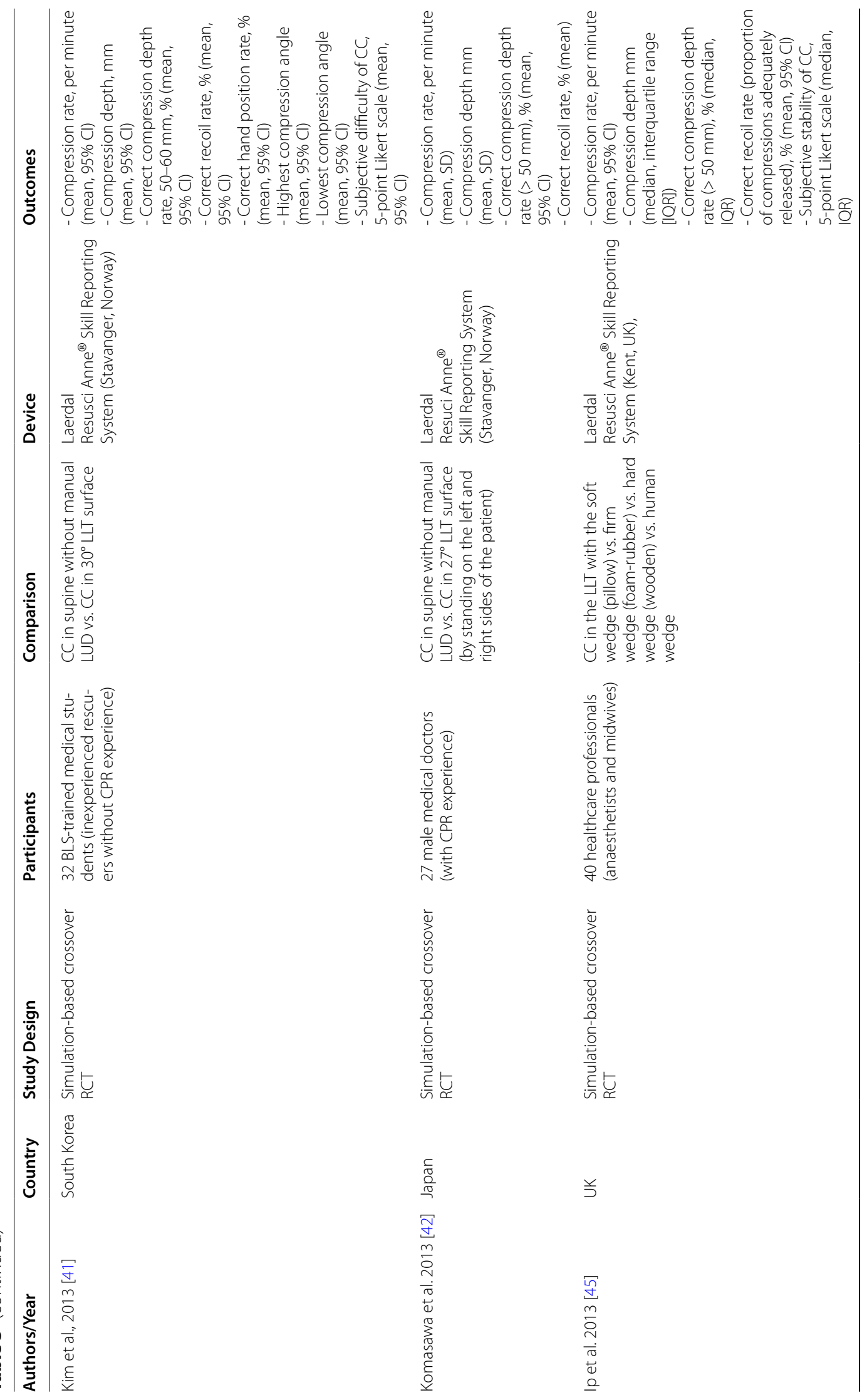




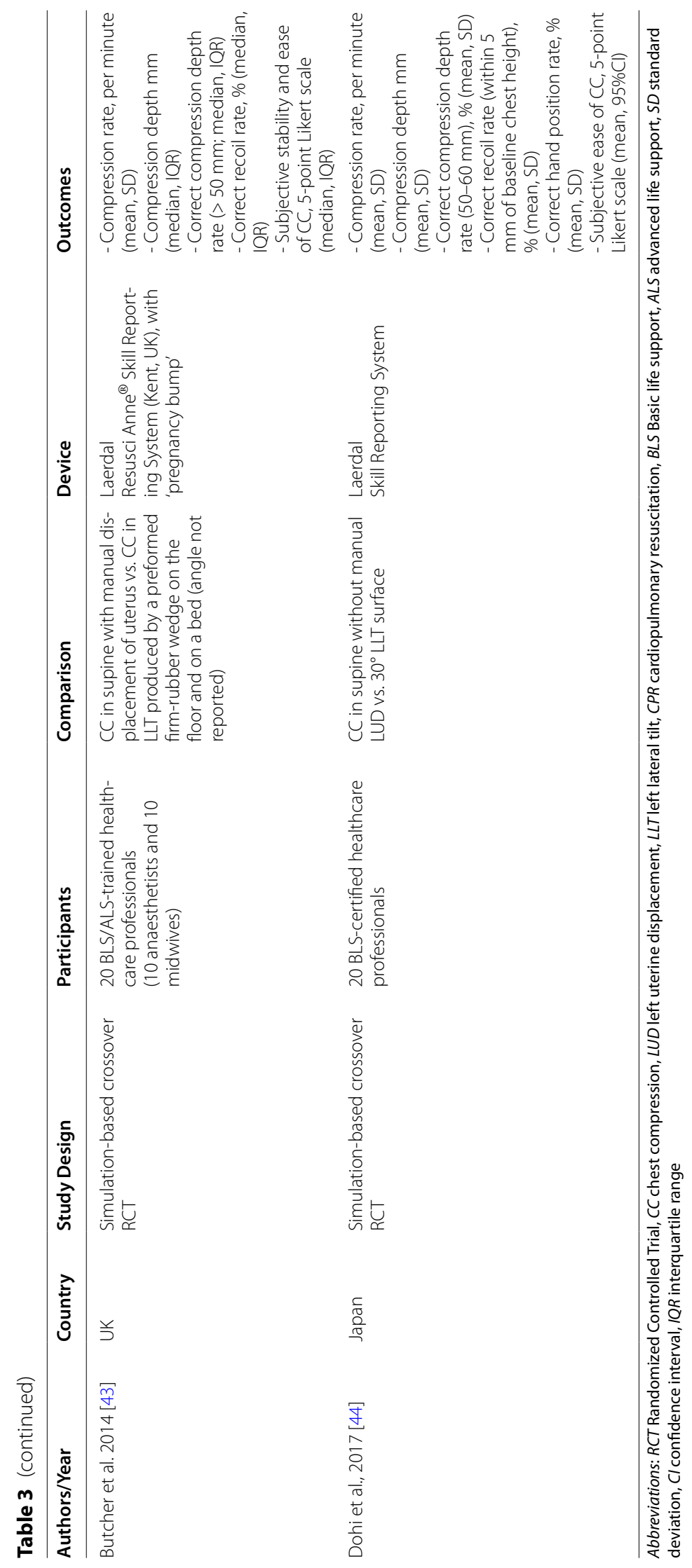


compression depth (median ranging from 40 to $44 \mathrm{~cm}$ ) and low rates of correct compression depth (median ranging from $25 \%$ to $57 \%$ ) were observed across all groups, indicating generally poor performance of chest compressions in the sample of this study.

\section{Subjective ease and stability of chest compression}

One study [43] involving inexperienced rescuers reported greater ease and stability of chest compressions in the supine position with manual left uterine displacement than in the left-lateral tilt position; the differences were statistically significant.

Comparison 2: left lateral tilt position $\left(27^{\circ}-30^{\circ}\right)$ vs. supine position without manual left uterine displacement Quality of chest compression

A total of five studies including four crossover RCTs $[40-42,44]$ and one nonrandomised crossover study [46] provided data on this outcome. Due to the methodological heterogeneity (i.e. RCTs or nonrandomised studies), only RCTs were included in the meta-analyses and results from nonrandomised study were presented separately in narrative form.

The four RCTs consistently showed no statistically significant differences between the supine and the leftlateral tilt position groups. Of these RCTs, one [42] was excluded from the meta-analysis (Fig. 2) because of insufficient data provided in the original study (the means and standard deviations were unreported).

A total of four RCTs [40-42, 44] assessed the rate of correct chest compression depth. The meta-analysis of these RCTs revealed the mean percentage of correct chest compression depth decreased by $18.77 \%$ when the left-lateral tilt position was used instead of the supine position; the difference was statistically significant (four RCTs, mean difference $[\mathrm{MD}]=-18.77,95 \% \mathrm{CI}=-28.89$, -8.64, $\operatorname{tau}^{2}=48.95, \mathrm{I}^{2}=47 \%$; Fig. 3). Subgroup analyses stratified by chest compression delivery surfaces (floor or bed) resulted in similar findings.

In addition, a meta-analysis of three RCTs [40-42] including a total of 89 health professionals revealed the mean chest compression depth was $2.88 \mathrm{~mm}$ lower in the $27^{\circ}-30^{\circ}$ left-lateral tilt position than in the supine position; the difference was statistically significant (three RCTs, MD $=-2.88 \mathrm{~mm}, 95 \% \mathrm{CI}=-4.19,-1.57, \mathrm{tau}^{2}=0$, $\mathrm{I}^{2}=0 \%$; Fig. 4). The results were consistent across subgroups defined by the surface (floor or bed).

A total of four RCTs [40-42, 44] reported the recoil rates, none of which indicated statistically significant differences between the supine and the left-lateral tilt groups, either on the floor or on the bed.

A total of three RCTs $[40,41,44]$ reported the rate of correct hand positioning during chest compressions. The

Table 4 Risk of bias assessment (judgement and supporting evidence) in the included studies using a revised Cochrane risk-of-bias tool for crossover trials

\begin{tabular}{|c|c|c|c|c|c|c|}
\hline & Bias due to randomisation & $\begin{array}{l}\text { Bias due to deviations from } \\
\text { intended interventions }\end{array}$ & $\begin{array}{l}\text { Bias due to missing } \\
\text { outcome data }\end{array}$ & $\begin{array}{l}\text { Bias due to outcome } \\
\text { measurement }\end{array}$ & $\begin{array}{l}\text { Bias due to selection of the } \\
\text { reported result }\end{array}$ & Overall \\
\hline \multicolumn{7}{|l|}{ RCTS } \\
\hline $\begin{array}{l}\text { Butcher } \\
\text { 2014 [39] }\end{array}$ & $\begin{array}{l}\text { Some concerns: Methods used } \\
\text { for randomisation and allocation } \\
\text { concealment not stated }\end{array}$ & $\begin{array}{l}\text { Some concerns: Washout period } \\
\text { to minimise the carryover effect } \\
\text { not stated }\end{array}$ & $\begin{array}{l}\text { Low risk: Outcome data } \\
\text { available for all participants } \\
\text { randomised }\end{array}$ & $\begin{array}{l}\text { Some concerns: Outcomes } \\
\text { assessed with a PC SkillReporting } \\
\text { system; blinding to the assessor } \\
\text { not reported }\end{array}$ & $\begin{array}{l}\text { Some concerns: Insufficient } \\
\text { information available to assess } \\
\text { the reporting bias }\end{array}$ & $\begin{array}{l}\begin{array}{l}\text { Some } \\
\text { concerns }\end{array} \\
\end{array}$ \\
\hline $\begin{array}{l}\text { Dohi } 2017 \\
{[40]}\end{array}$ & $\begin{array}{l}\text { Some concerns: Methods used } \\
\text { for randomisation and allocation } \\
\text { concealment not stated }\end{array}$ & $\begin{array}{l}\text { Low risk: 'Resting for } 10 \mathrm{~min} . . . \\
\text { and repeating CPR for } 2 \mathrm{~min} \text { in } \\
\text { the second assigned position' }\end{array}$ & $\begin{array}{l}\text { Low risk: Outcome data } \\
\text { available for all participants } \\
\text { randomised }\end{array}$ & $\begin{array}{l}\text { Low risk: 'To avoid potential } \\
\text { bias, rescuers were blinded to the } \\
\text { monitor screen displaying } \\
\text { compression rate or hand position' }\end{array}$ & $\begin{array}{l}\text { Some concerns: Insufficient } \\
\text { information available to assess } \\
\text { the reporting bias }\end{array}$ & $\begin{array}{l}\text { Some } \\
\text { concerns }\end{array}$ \\
\hline $\begin{array}{l}\text { Ip 2013 } \\
{[41]}\end{array}$ & $\begin{array}{l}\text { Some concerns: Randomisation } \\
\text { by drawing lots/allocation } \\
\text { concealment not stated }\end{array}$ & $\begin{array}{l}\text { Low risk: 'Sufficient breaks } \\
\text { between tests' were taken to } \\
\text { minimise the carryover effect }\end{array}$ & $\begin{array}{l}\text { Low risk: Outcome data } \\
\text { available for almost all } \\
\text { participants, although 'one of } \\
\text { the participants ... [was] } \\
\text { excluded from analysis due to } \\
\text { incomplete data capture' }\end{array}$ & $\begin{array}{l}\text { Some concerns: Outcomes } \\
\text { assessed with a PC SkillReporting } \\
\text { system; blinding to the assessor } \\
\text { not reported }\end{array}$ & $\begin{array}{l}\text { Some concerns: Insufficient } \\
\text { information available to assess } \\
\text { the reporting bias }\end{array}$ & $\begin{array}{l}\text { Some } \\
\text { concerns }\end{array}$ \\
\hline $\begin{array}{l}\text { Kim } 2012 \\
{[37]}\end{array}$ & $\begin{array}{l}\text { Some concerns: Methods used } \\
\text { for randomisation and allocation } \\
\text { concealment not stated }\end{array}$ & $\begin{array}{l}\text { Low risk: 'The participant rested } \\
\text { for } 10 \text { min to minimise rescuer } \\
\text { fatigue' between tests }\end{array}$ & $\begin{array}{l}\text { Low risk: Outcome data } \\
\text { available for all participants } \\
\text { randomised }\end{array}$ & $\begin{array}{l}\text { Low risk: 'To avoid potential } \\
\text { bias, participants were blinded to } \\
\text { the monitor screen' }\end{array}$ & $\begin{array}{l}\text { Some concerns: Insufficient } \\
\text { information available to assess } \\
\text { the reporting bias }\end{array}$ & $\begin{array}{l}\text { Some } \\
\text { concerns }\end{array}$ \\
\hline $\begin{array}{l}\text { Komasawa } \\
2013[38]\end{array}$ & $\begin{array}{l}\text { Some concerns: Methods used } \\
\text { for randomisation and allocation } \\
\text { concealment not stated }\end{array}$ & $\begin{array}{l}\text { Some concerns: Washout period } \\
\text { to minimise the carryover effect } \\
\text { not stated }\end{array}$ & $\begin{array}{l}\text { Low risk: Outcome data } \\
\text { available for all participants } \\
\text { randomised }\end{array}$ & $\begin{array}{l}\text { Some concerns: Outcomes } \\
\text { assessed with a PC SkillReporting } \\
\text { system; blinding to the assessor } \\
\text { not reported }\end{array}$ & $\begin{array}{l}\text { Some concerns: Insufficient } \\
\text { information available to assess } \\
\text { the reporting bias }\end{array}$ & $\begin{array}{l}\begin{array}{l}\text { Some } \\
\text { concerns }\end{array} \\
\end{array}$ \\
\hline $\begin{array}{l}\text { Lee } 2011 \\
{[36]}\end{array}$ & $\begin{array}{l}\text { Some concerns: Methods used } \\
\text { for randomisation and allocation } \\
\text { concealment not stated }\end{array}$ & $\begin{array}{l}\text { Some concerns: Washout period } \\
\text { to minimise the carryover effect } \\
\text { not stated }\end{array}$ & $\begin{array}{l}\text { Low risk: Outcome data } \\
\text { available for all participants } \\
\text { randomised }\end{array}$ & $\begin{array}{l}\text { Some concerns: Outcomes } \\
\text { assessed with a PC SkillReporting } \\
\text { system; blinding to the assessor } \\
\text { not reported }\end{array}$ & $\begin{array}{l}\text { Some concerns: Insufficient } \\
\text { information available to assess } \\
\text { reporting bias }\end{array}$ & $\begin{array}{l}\text { Some } \\
\text { concerns }\end{array}$ \\
\hline \multicolumn{7}{|l|}{ Non-RCTs } \\
\hline $\begin{array}{l}\text { Goodwin } \\
1992[42]\end{array}$ & $\begin{array}{l}\text { High risk: } \\
\text { Not stated as being randomised }\end{array}$ & $\begin{array}{l}\text { Some concerns: Washout period } \\
\text { to minimise the carryover effect } \\
\text { not stated }\end{array}$ & $\begin{array}{l}\text { Low risk: Outcome data } \\
\text { available for all participants } \\
\text { randomised }\end{array}$ & $\begin{array}{l}\text { High risk: The definitions of the } \\
\text { outcomes were not clearly defined. } \\
\text { Outcomes assessed with a PC } \\
\text { SkillReporting system; blinding to } \\
\text { the assessor not reported }\end{array}$ & $\begin{array}{l}\text { Some concerns: Insufficient } \\
\text { information available to assess } \\
\text { the reporting bias }\end{array}$ & High risk \\
\hline $\begin{array}{l}\text { Rees and } \\
\text { Wills } 1988 \\
{[43]}\end{array}$ & $\begin{array}{l}\text { High risk: } \\
\text { Not stated as being randomised }\end{array}$ & $\begin{array}{l}\text { Some concerns: Washout period } \\
\text { to minimise the carryover effect } \\
\text { not stated }\end{array}$ & $\begin{array}{l}\text { Low risk: Outcome data } \\
\text { available for all participants } \\
\text { randomised }\end{array}$ & $\begin{array}{l}\text { High risk: Outcomes assessed } \\
\text { with a transducer developed by the } \\
\text { researcher; blinding to the assessor } \\
\text { not reported }\end{array}$ & $\begin{array}{l}\text { Some concerns: Insufficient } \\
\text { information available to assess } \\
\text { the reporting bias }\end{array}$ & High risk \\
\hline
\end{tabular}


results of the meta-analysis indicated the correct hand position rate was $9 \%$ lower with the patient mannequin in the left-lateral tilt position than with it in the supine position (three RCTs, $\mathrm{MD}=-9.14,95 \% \mathrm{CI}=-17.8,-0.48$, tau $^{2}$ $=0, \mathrm{I}^{2}=0 \%$; Figure 5).

There was one non-randomised crossover study conducted in 1992 [46] which reported that chest compression was significantly better (with the mean percentage of correct cardiac compression being approximately $34 \%$ higher) in the wedged position than in the supine position. The author stated that a common reason for inaccuracies is 'compression of too great a force' ([46], p. 434), but neither the definition of correct cardiac compression nor compression force was provided.

\section{Subjective difficulty (or ease) of chest compressions}

Two RCTs [41, 44] involving both experienced and inexperienced rescuers reported that performing chest compressions in the left-lateral tilt position was significantly more difficult than doing so in the supine position, whereas another RCT [40] including only experienced emergency medical doctors reported no difference in the subjective difficulty between the two positions.

\section{Quality of ventilation}

One nonrandomised crossover study [46] involving 18 midwives reported there was no statistically significate difference in the percentage of correct expired air ventilations (during performance of mouth-to-mouth resuscitation) between the supine and the left literal tilt positions (mean $[\mathrm{SD}]=62.2 \%[21.4]$ in the supine vs. 56.7\% [27.7] in the left literal tilt positions). However, the definition of correct expired air ventilations was not described in the original study; it noted only that the commonest course of inaccurate ventilation was the ventilation of small volume.

Comparison 3: methods for producing left lateral tilt position (soft vs. firm vs. hard vs. human wedge) Quality of chest compression

One crossover RCT reported that the type of wedge the soft wedge (pillow), firm wedge (foam-rubber), hard wedge (wooden) or human wedge - had no effect on the average rate or adequate release of chest compressions. The study consistently indicated that the depth of compressions (compression depth $[\mathrm{mm}]$ and rate of correct compression depth $>50 \mathrm{~mm}$ ) was reduced with the human wedge compared with other wedges; the differences were statistically significant during chest compressions on the floor but not on the bed.

\section{Subjective stability of chest compressions}

One crossover RCT reported that the firm and hard wedges were the most stable (stability rated as 'good' or 'very good'), whereas the soft wedges were the least stable during chest compressions during chest compression on either the floor or bed.

Comparison 4: chest compressions in various angles $\left(0^{\circ}\right.$, $27^{\circ}, 32^{\circ}, 49^{\circ}$ and $90^{\circ}$ ) of inclination Quality of chest compression

In one nonrandomised trial [47] involving eight medical doctors, the maximum possible resuscitative force (as measured with calibrated force transducer fitted on the plane) decreased as the angle of inclination of the plane increased, from $67 \%$ of body weight in the supine position to $36 \%$ in the full lateral.

\section{Discussion}

Our systematic review evaluated the effect of maternal positioning for successful resuscitation of pregnant women. We identified no studies that evaluated the outcomes with real maternal patients. However, there were eight simulation-based crossover trials (six RCTs and two non-RCTs) that specifically examined the impact of maternal positioning or strategies on the quality of chest compression for hypothetical cardiac arrest maternal patients using a mannequin. Overall, meta-analyses of RCTs indicated resuscitation in the supine position enhances the quality of chest compressions by increasing the rates of correct compression depth and correct hand position, compared with resuscitation in the $27^{\circ}-30^{\circ}$ leftlateral tilt position in pregnant women. The results were consistent for chest compressions performed both on the bed and on the floor. This review also suggested chest compressions in the left-lateral tilt position may be more difficult than chest compressions in the supine position for inexperienced health professionals.

\section{Quality of evidence}

For all the outcomes included in this review, the quality of evidence was rated as very low using the GRADE criteria. The certainty of evidence was downgraded for risk of bias, indirectness, inconsistency and imprecision of results. More specifically, we downgraded one level for a potential risk of bias due to the randomisation process, 


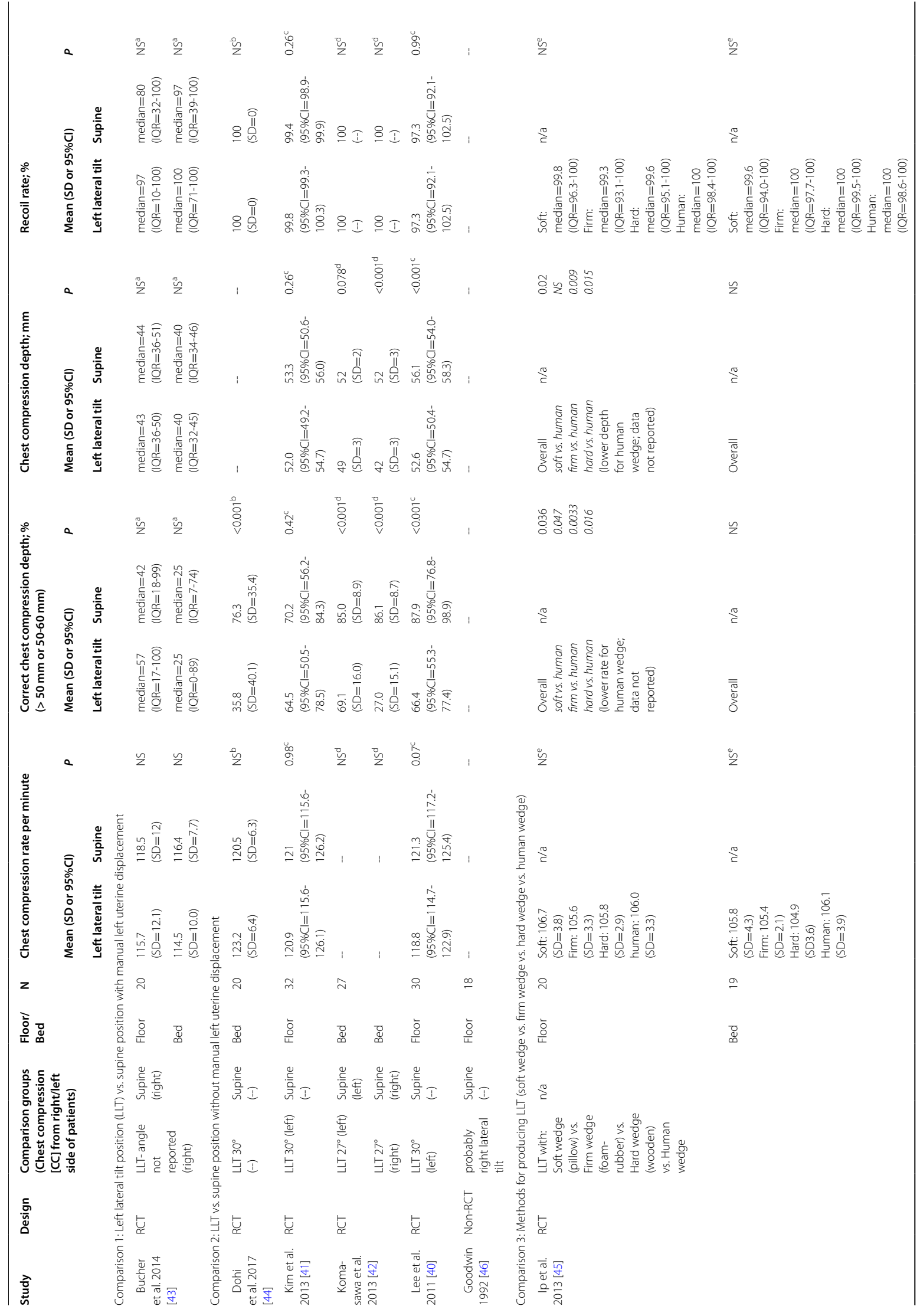


e $\quad \begin{array}{lll}\infty & \\ 0 & 0 \\ 0 & 0 \\ 0 & 0 \\ 0\end{array}$

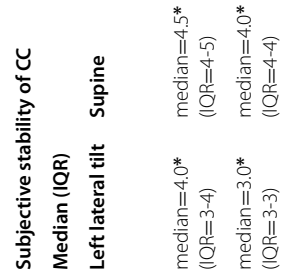

2
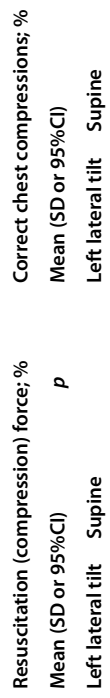

e

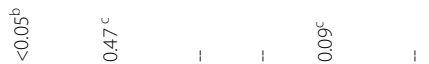

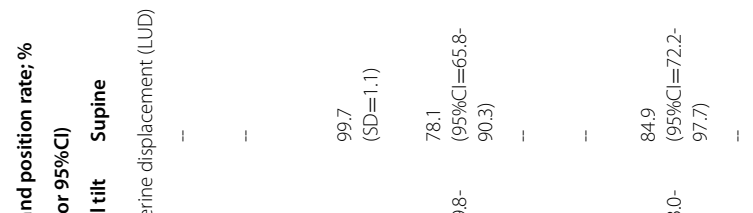

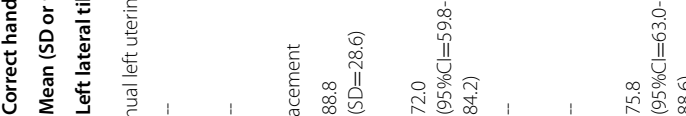

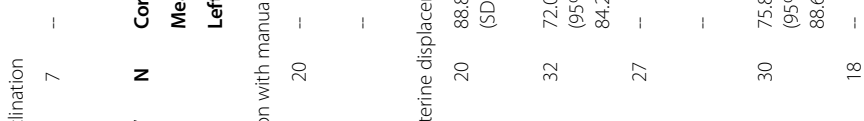

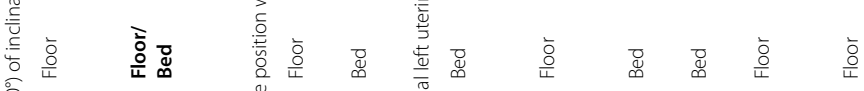

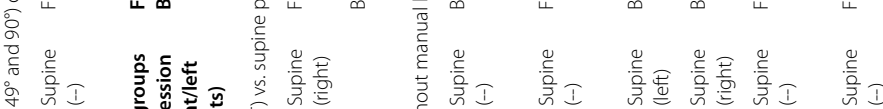

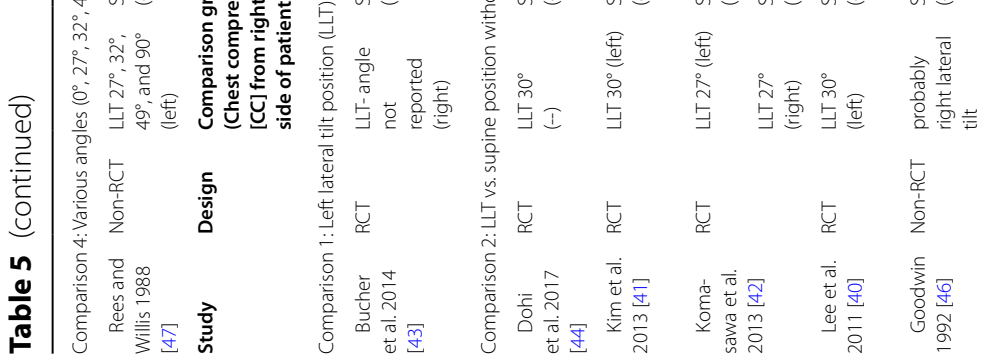


$\bar{\delta}$

$\bar{\Xi}$

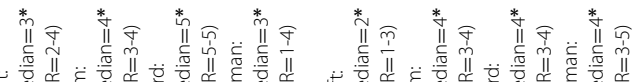

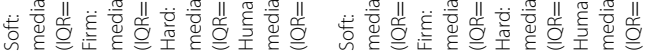
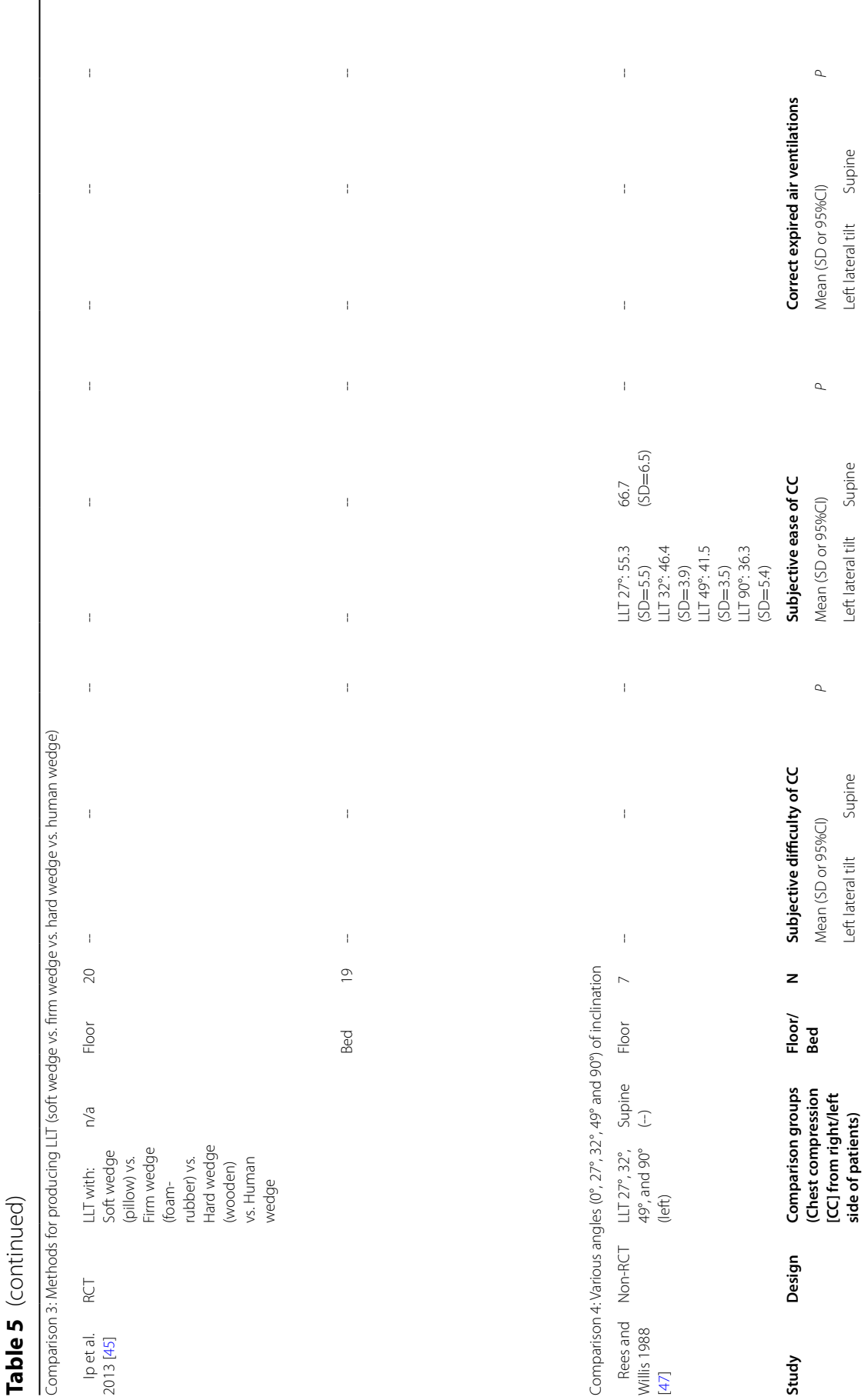

吾

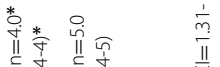

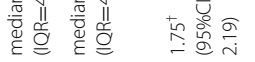

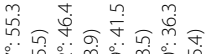

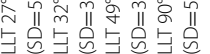

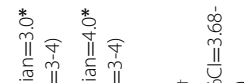

密

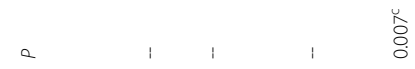

ฐ

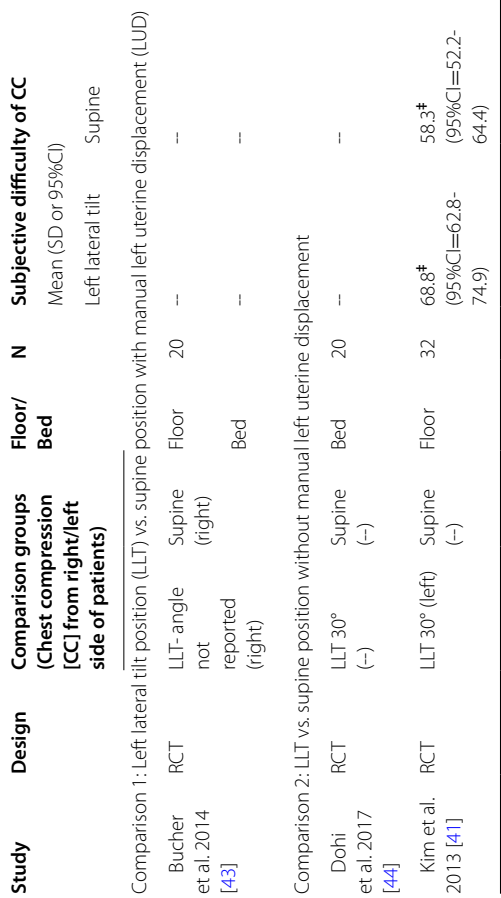




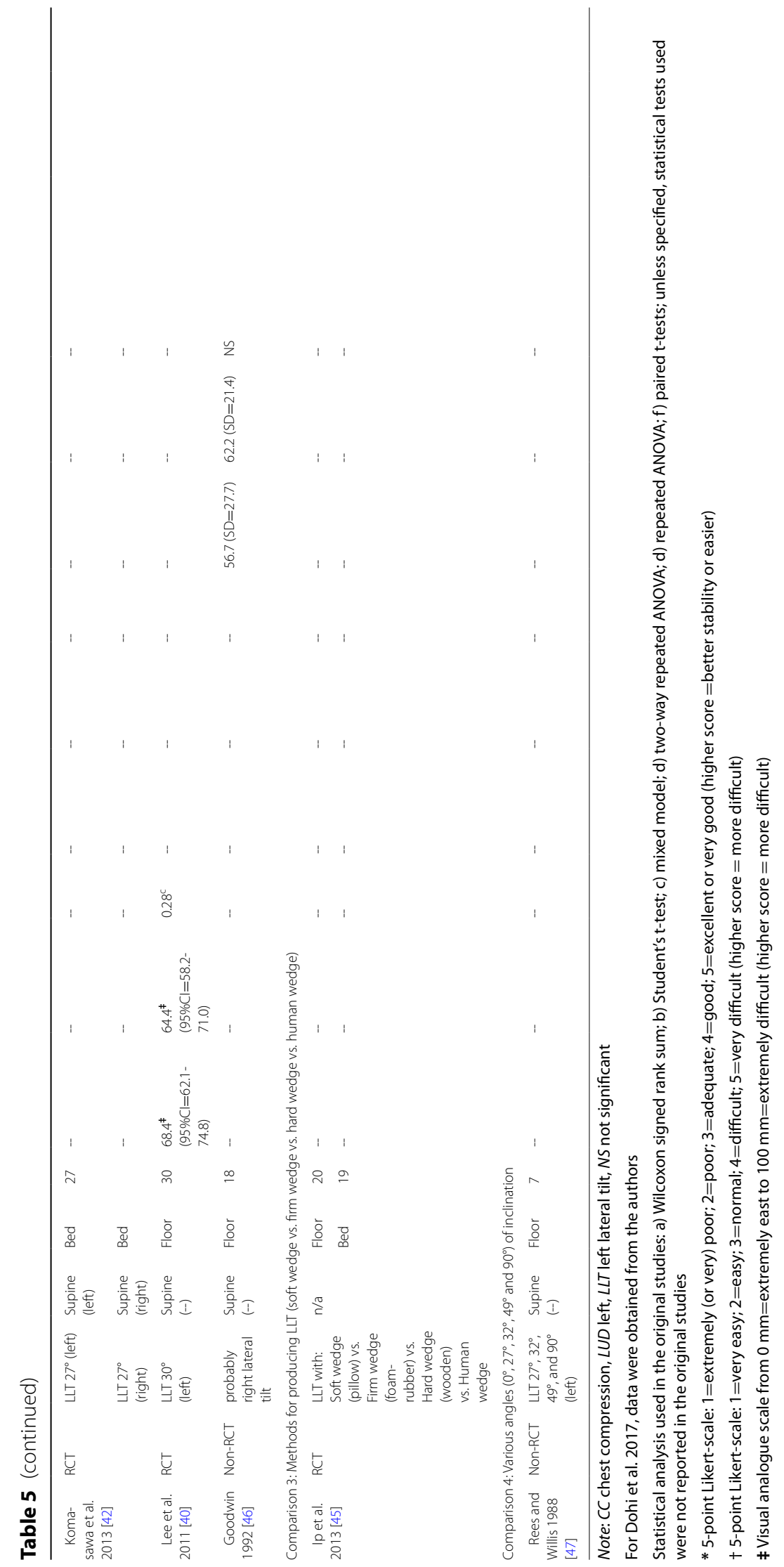




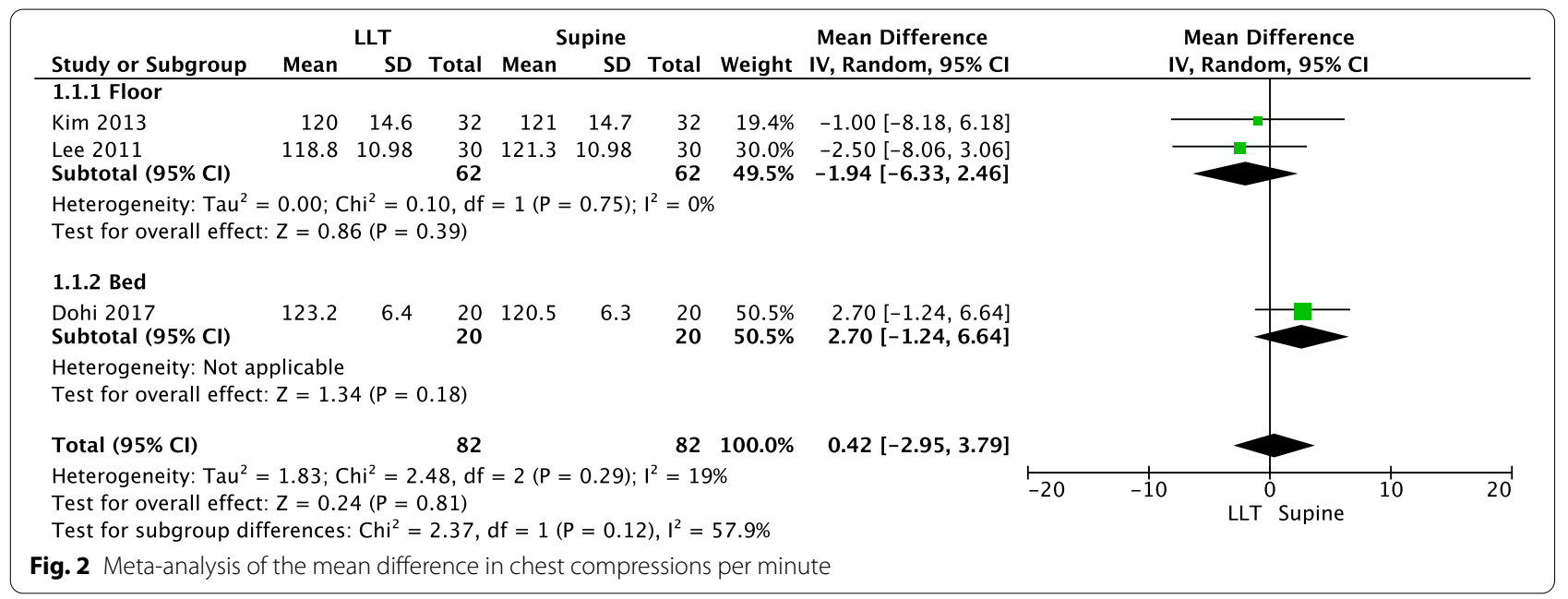

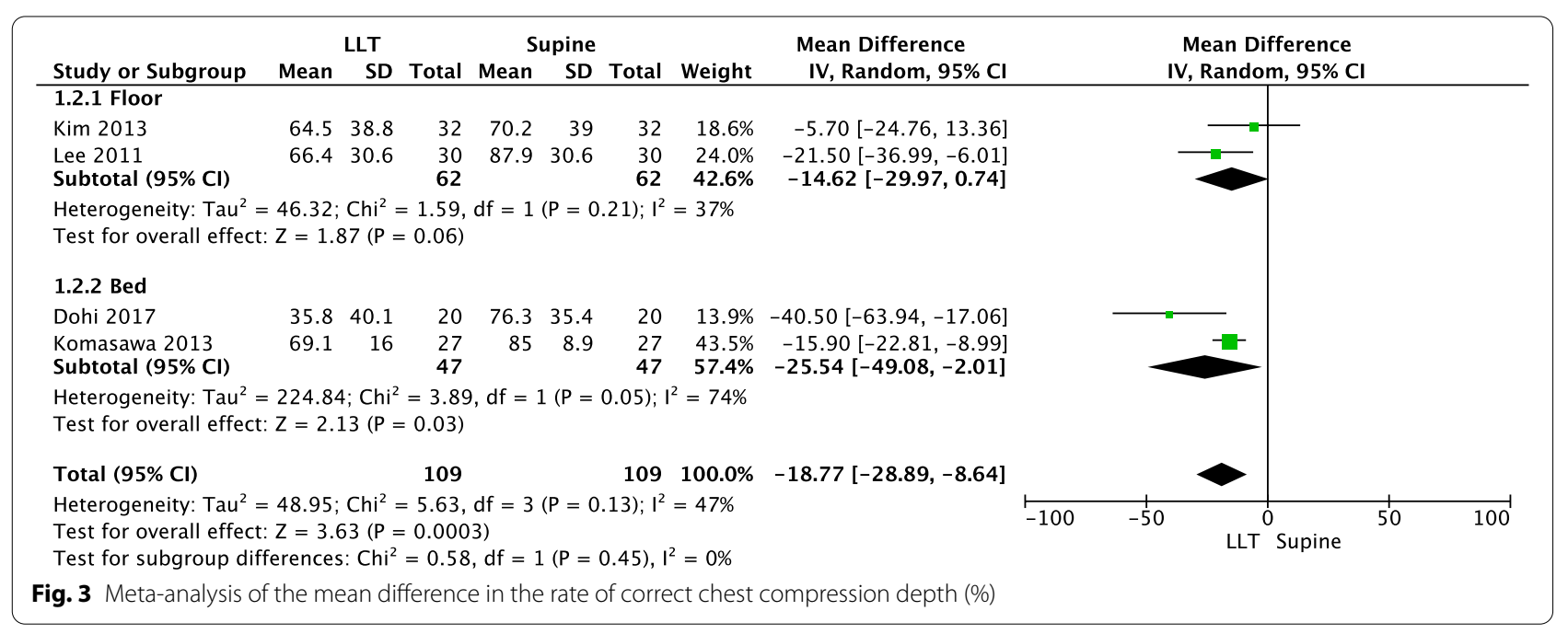

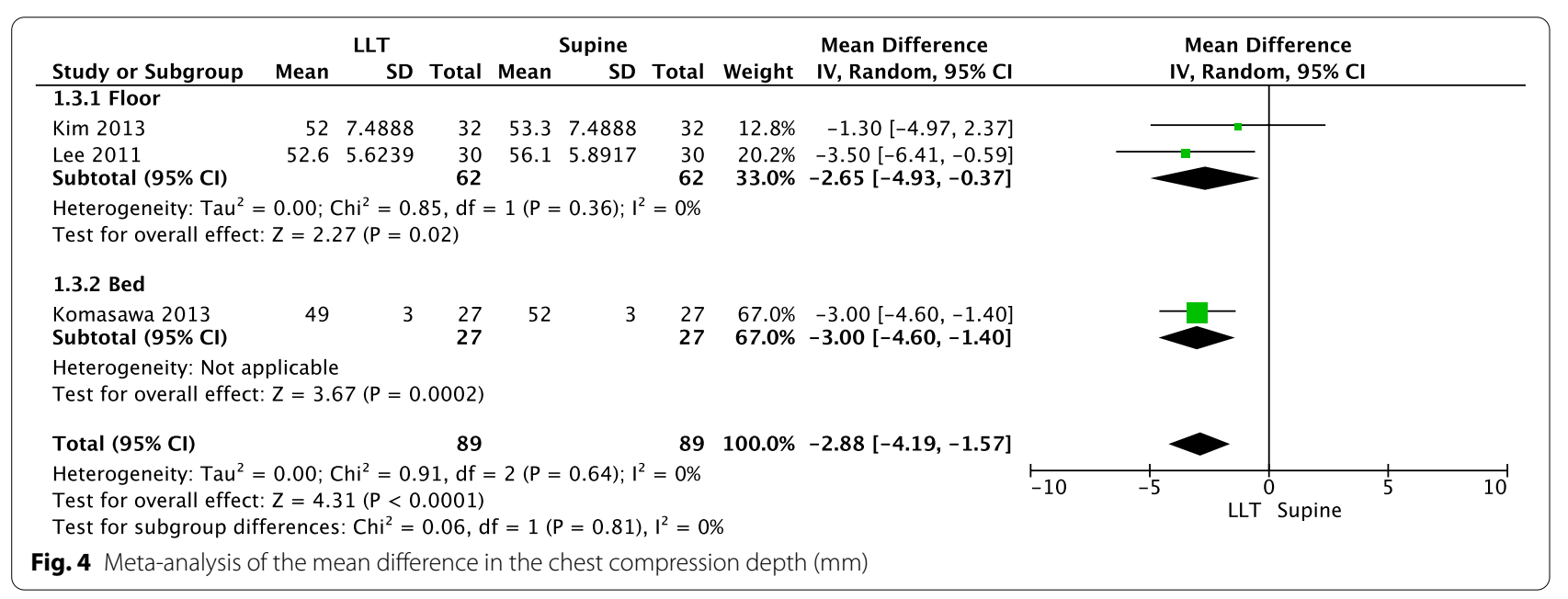




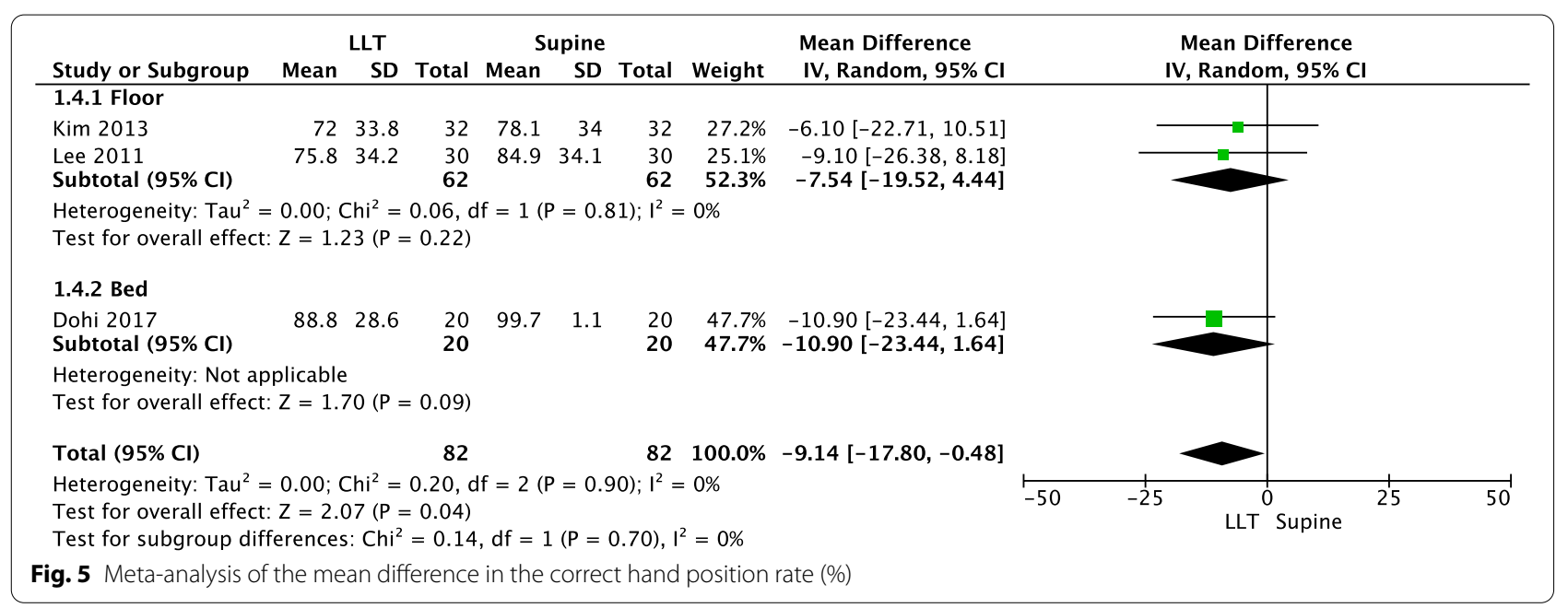

insufficient washout period between phases and/or unblinding of participants for all the outcomes measuring for quality of CPR. We also downgraded two levels for indirectness of evidence because all the outcome was assessed with simulation-based studies using hypothetical cardiac arrest maternal patient mannequins. We further downgraded one level for serious unexplained inconsistency (heterogeneity) for quality of chest compression as measured with correct chest compression depth rate and another one for serious imprecision (wide confidence intervals) of the mean effect for correct chest compression depth rate and correct hand position rate.

Study effect estimates for quality of chest compression varied between RCTs and nonrandomised study with conflicting results; RCTs favouring the spine position and nonrandomised study [46] favouring the left-lateral tilt position. The nonrandomised study was published in 1992, whereas RCTs were published more recently, in the 2010s.Some of this variation is likely to be caused by differences in the definition used for measuring quality of chest compression that reflect changes in the clinical guidelines' recommendations for CPR in past decades, which we discuss further in the Comparison with Existing Guidelines and Reviews section below. There is a lack of clarity of the definition of high-quality chest compression and high risk of selection bias due to a lack of randomisation in the non-randomised study. Therefore, we only included the results from RCTs in the meta-analyses.

Heterogeneity is not a reason for downgrading the evidence for quality of CPR apart from quality of chest compression as measured using the percentage of correct chest compression depth $\left(\mathrm{Tau}^{2}=48.95, \mathrm{I}^{2}=47 \%\right)$. The percentage of correct chest compression depth was consistently lower in the left-lateral tilt position than the supine position. However, the effect of size (mean difference in the percentage of correct chest compression depth) varied from study to study: three appear to have large effects (15.9-40.5\%) and one much smaller effect (5.7\%). There are many probable causes of heterogeneity, which cannot be explained by a subgroup analysis by chest compression delivery surfaces (floor or bed) or study population (experienced or inexperienced rescuers). The estimated effect of maternal positioning is larger, $57 \%$ [42], when a chest compression was performed from patients' right side, showing lower correct percentage $(27 \%)$ in the left-lateral tilt position, compared with the spine position (86\%). We need more studies to gain a reliable estimate of heterogeneity and reasons for it.

\section{Comparison with existing guidelines and reviews}

The 2020 American Heart Association (AHA) Guidelines [48] recommend that "priorities for the pregnant woman in cardiac arrest should include provision of high-quality CPR and relief of aortocaval compression through leftlateral uterine displacement" (Supplement, p. 454). This recommendation is based primarily on the physiology of pregnancy, extrapolations from the non-arrest pregnancy states $[49,50]$ and non-randomised simulation-based studies [46, 47]. However, the interpretation of the recommendation is not straightforward because the recommendation was based on inconsistent results, including the non-randomised simulation-based studies [46, 47] conducted 30 to 40 years ago.

One of the studies often utilised in clinical practice guidelines is Goodwin's non-randomised simulationbased study published in 1992 [46]. Goodwin found that chest compression quality was more reduced in the supine position than in the wedged position, using the 
human wedge manoeuvre. According to Goodwin, the common reason for inaccuracy is "compression of too great a force" ([46], p. 434), but the correct definition of cardiac compression and compression were not provided. Our systematic review revealed that findings from recent RCTs contradict Goodwin's findings, possibly because of changes in CPR recommendations in past decades [51]. For example, the current CPR guidelines recommend a target chest compression depth of 5-6 cm, whereas it was $4-5 \mathrm{~cm}$ (AHA Guidelines 2005) in the past. Even further back, it was defined as the difference in the height of a rescuer's shoulder, not in a victim's chest, using 2.5-5 $\mathrm{cm}$ in the 1992 AHA Guidelines [52].

Although our review included only indirect evidence from simulation-based studies, the trials included had more sophisticated studies that overcome the methodological limitations commonly observed in previous studies (such as lack of randomisation, the potential risk of carryover effect and the inaccuracy of measuring outcomes). Our results showed that resuscitation in the supine position enhances the quality of the resuscitation activity. Together with evidence from previous systematic reviews on the non-arrest pregnant population $[17,53]$ that shows that manual left uterine displacement effectively relieves aortocaval pressure in pregnant women with hypotension, it is reasonable to conclude that manual left uterine displacement in the supine position is more effective than a left-lateral tilt position to increase the chest compression quality during resuscitation. This can, in turn, contribute to increased maternal and foetal survival rates following maternal cardiac arrest.

\section{Strengths and limitations of the review}

Given its systematic and comprehensive literature search, our review enhanced evidence regarding the effect of maternal positioning during maternal CPR, particularly on the quality of chest compressions. Where we found information in the included studies to be insufficient, we contacted the original researcher, if doing so was possible. However, the quality of evidence produced by our systematic review was still poor, mainly because of indirect evidence from the mannequin studies.

We did not identify any study that evaluated the effect of maternal positioning using real patients. Therefore, there were no data on survival rates and the return of spontaneous circulation following maternal cardiac arrest. Foetal/neonatal outcomes were also unavailable. Thus, the only outcomes available constituted indirect evidence of the quality of CPR, which was obtained from simulation-based studies using hypothetical cardiac arrest maternal patient mannequins. Therefore, there are serious limitations regarding the applicability and transferability of the findings of our systematic review to real maternal patients.

From the study design point of view, all studies included in our review were crossover trials in which each healthcare professional involved performed chest compressions on a mannequin in two or more maternal positions in random order. Because each participant acted as their own control, this design allowed them to express the difficulty with chest compressions that they experienced during a particular maternal position. The crossover trials could have provided more precise effect size estimates than parallel-group trials if appropriate statistical analyses (paired analyses) had been applied $[54,55]$. However, this was not the case in some of our included studies. Data on within-subjects correlation were unavailable, so this advantage of a crossover design could not be utilised. Our meta-analysis estimated the average effect of an intervention (maternal positioning), but given the small number of studies to be synthesised for each outcome, the statistical model used for the metaanalysis (random effects model) could not estimate the between-study variance (the extent of variation among the effects observed in different studies).

\section{Further research}

Knowledge gaps still exist concerning the effect and efficacy of CPR with manual uterine displacement versus tilt positioning on clinical outcomes following maternal cardiac arrest. Simulation-based RCTs specifically designed to evaluate the favourable or unfavourable effects of manual left uterine displacement should be carried out to assess the quality of CPR, including delay and interruption of CPR in relation to performing manual left uterine displacement. Further studies also must focus on establishing what could be the best strategies (including for manual left uterine displacement) for high-quality $\mathrm{CPR}$. This is important because there are various recommendations regarding manual left uterine displacement, possibly referencing the situations or settings wherein maternal cardiac arrest occurs. For example, guidelines recommend 'placing a hand below the uterus on the maternal right and pushing the uterus slightly upwards and to the left' ([50], p.29), which can be done with onehand or two-hand techniques and from the left or right side of the patient $[24,48,56]$. There is, however, a lack of evidence about whether and how these different strategies affect the quality of CPR. Because maternal cardiac arrest is rare and RCTs evaluating the effects of maternal position with real patients would be unrealistic, the development of a nationwide database that collects data concerning both in-hospital and out-of-hospital maternal cardiac arrest patients would be beneficial. Such a database would be critical to predict the clinical outcomes of 
such cases, including the survival rates of mothers and babies with favourable neurologic outcomes, after cardiac arrest vis-à-vis the strategies used for relieving aortocaval compression during maternal resuscitation.

\section{Conclusion}

Although rare, cardiac arrest during pregnancy is the leading cause of maternal death. Recently, its incidence has been increasing worldwide because more pregnant women have risk factors. The provision of early, highquality cardiopulmonary resuscitation (CPR) plays a major role in the increased likelihood of survival. Therefore, clinicians should be familiar with its management. Because of the aortocaval compression caused by the gravid uterus, clinical guidelines often emphasise the importance of maternal positioning during CPR, but there has been little evidence regarding which position is most effective. Our systematic review synthesised evidence from trials published in recent years, which should provide guidance on updating clinical practice guidelines. The meta-analyses showed that resuscitation of pregnant women in the $27^{\circ}-30^{\circ}$ left-lateral tilt position resulted in lower quality chest compressions. The difference is an 19 and $9 \%$ reduction in compression depth rates and hand position, respectively, than resuscitations in the supine position. Inexperienced clinicians find it difficult to perform chest compressions in the left-lateral tilt position. Given that manual left uterine displacement allows the patient to remain supine, the resuscitation of women in the supine position using manual left uterine displacement should continue to be supported. Further research is needed to fill knowledge gaps regarding the effects of maternal positioning on clinical outcomes, such as survival rates following maternal cardiac arrest.

\section{Abbreviations}

ALS: Advanced life support; BLS: Basic life support; CPR: Cardiopulmonary resuscitation; LLT: Left lateral tilt; LUD: Left uterine displacement; RCT: Randomised Controlled Trial.

\section{Acknowledgements \\ The authors would like to thank the members of Japan Resuscitation Council Maternal task force and editorial board; Dr. Rie Kato, Dr. Shinji Takahashi, Dr. Jun Takeda, Dr. Masahiro Nakao, Dr. Eishin Nakamura, Dr. Masafumi Nii, Dr. Yoshihiro Yamahata, Dr. Makoto Tsuji, Dr. Takahide Maenaka, Dr. Shinji Baba, and Dr. Yuki Hosokawa, members of Japan Resuscitation Council; Dr. Hiroshi Nonogi, Dr. Mayuki Aibiki, Dr. Takanari Ikeyama, Dr. Tetsuya Isayama, Dr. Taku Iwami, Dr. Yasuhiro Kuroda, Dr. Tetsuya Sakamoto, Dr. Naoki Shimizu, Dr. Masao Nagayama, Dr. Chika Nishiyama, Dr. Tetsuo Hatanaka, Dr. Shigeharu Hosono, Dr. Tasuku Matsuyama.}

\section{Authors' contributions}

Drs Enomoto, Yamashita, Furuta, Tanaka, Matsunaga and Sakurai conceptualized and designed the study and developed search strategies. Drs Enomoto and Furuta designed the data extraction sheet. Drs Furuta and $\mathrm{Ng}$ extracted data analysed and interpreted data. Drs Enomoto, Yamashita, Furuta and Tanaka drafted the manuscript. Drs Matsunaga, Sakurai and Ng reviewed and revised the manuscript. All authors approved the final manuscript as submitted and agreed to be accountable for all aspects of the work.

\section{Funding}

This research received no specific grant from any funding agency in the public, commercial, or not-for-profit sectors.

\section{Availability of data and materials}

The datasets used and/or analysed during the current study are available from the corresponding author on reasonable request.

\section{Declarations}

Ethics approval and consent to participate

Not applicable

\section{Consent for publication}

Not applicable

\section{Competing interests}

The authors declare that they have no competing interests.

\section{Author details}

${ }^{1}$ Department of Obstetrics and Gynaecology, Graduate School of Medicine, Mie University / Mie University Hospital, 2-174 Edobashi, Tsu, Mie 514-8507, Japan. ${ }^{2}$ Department of Emergency and Critical Care Medicine, Japanese Red Cross Medical Center, Tokyo, Japan. ${ }^{3}$ Department of Human Health Sciences, Graduate School of Medicine, Kyoto University, Kyoto, Japan. ${ }^{4}$ London School of Hygiene \& Tropical Medicine, London, UK. ${ }^{5}$ Department of Obstetrics and Gynaecology, Saitama Medical Centre, Saitama Medical University, Saitama, Japan. ${ }^{6}$ Division of Emergency and Critical Care Medicine, Department of Acute Medicine, Nihon University School of Medicine, Tokyo, Japan.

Received: 11 August 2021 Accepted: 13 December 2021

Published online: 25 February 2022

\section{References}

1. Briller J. Cardiopulmonary resuscitation of pregnant women. In: Elkayam $U$, editor. Cardiac problems in pregnancy. 4th ed. Hoboken: Wiley Blackwell; 2020.

2. Balki M, Liu S, Leon JA, Baghirzada L. Epidemiology of cardiac arrest during hospitalization for delivery in Canada: a nationwide study. Anesth Analg. 2017;124(3):890-7.

3. Beckett VA, Knight M, Sharpe P. The CAPS Study: incidence, management and outcomes of cardiac arrest in pregnancy in the UK: a prospective, descriptive study. BJOG. 2017;124(9):1374-81.

4. Mhyre JM, Tsen LC, Einav S, Kuklina EV, Leffert LR, Bateman BT. Cardiac arrest during hospitalization for delivery in the United States, 1998-2011. Anesthesiology. 2014;120(4):810-8.

5. Schaap TP, Overtoom E, van den Akker T, Zwart JJ, van Roosmalen J, Bloemenkamp KWM. Maternal cardiac arrest in the Netherlands: a nationwide surveillance study. Eur J Obstet Gynecol Reprod Biol. 2019;237:145-50.

6. Jeejeebhoy F, Windrim R. Management of cardiac arrest in pregnancy. Best Pract Res Clin Obstetr Gynaecol. 2014;28(4):607-18.

7. Tanaka H, Katsuragi S, Osato K, Hasegawa J, Nakata M, Murakoshi T, et al. The increase in the rate of maternal deaths related to cardiovascular disease in Japan from 1991-1992 to 2010-2012. J Cardiol. 2017;69(1):74-8.

8. Knight M, Clarke B, Head C, James R, Kotnis R, Lucas S, et al. Lessons on cardiovascular care. In: Knight M, Bunch K, Tuffnell D, Shakespeare J, Kotnis R, Kenyon S, Kurinczuk JJEM-U, editors. Saving lives, improving mothers' care - lessons learned to inform maternity care from the UK and Ireland confidential enquiries into maternal deaths and morbidity 201517. Oxford: National Perinatal Epidemiology Unit, University of Oxford; 2019. p. 20-44.

9. Kikuchi J, Deering S. Cardiac arrest in pregnancy. Semin Perinatol. 2018;42(1):33-8.

10. Mehta LS, Warnes CA, Bradley E, Burton T, Economy K, Mehran R, et al. Cardiovascular considerations in caring for pregnant patients: a 
scientific statement from the American Heart Association. Circulation. 2020;141(23):e884-903.

11. Zelop CM, Einav S, Mhyre JM, Martin S. Cardiac arrest during pregnancy: ongoing clinical conundrum. Am J Obstet Gynecol. 2018;219(1):52-61.

12. Dijkman A, Huisman CM, Smit M, Schutte JM, Zwart JJ, van Roosmalen JJ, et al. Cardiac arrest in pregnancy: increasing use of perimortem caesarean section due to emergency skills training? BJOG. 2010;117(3):282-7.

13. Ramachandran SK, Mhyre J, Kheterpal S, Christensen RE, Tallman K, Morris $M$, et al. American Heart Association's get with the guidelines-resuscitation I: predictors of survival from perioperative cardiopulmonary arrests: a retrospective analysis of 2,524 events from the get with the guidelinesresuscitation registry. Anesthesiology. 2013;119(6):1322-39.

14. Lipowicz AA, Cheskes S, Gray SH, Jeejeebhoy F, Lee J, Scales DC, et al. Incidence, outcomes and guideline compliance of out-of-hospital maternal cardiac arrest resuscitations: a population-based cohort study. Resuscitation. 2018;132:127-32.

15. Jeejeebhoy FM, Zelop CM, Lipman S, Carvalho B, Joglar J, Mhyre JM, et al. Cardiac arrest in pregnancy: a scientific statement from the American Heart Association. Circulation. 2015;132(18):1747-73.

16. Helviz Y, Einav S. Maternal cardiac arrest. Curr Opin Anaesthesiol. 2019;32(3):298-306.

17. Cluver C, Novikova N, Hofmeyr GJ, Hall DR. Maternal position during caesarean section for preventing maternal and neonatal complications. Cochrane Database Syst Rev. 2013;(3):CD007623.

18. Chesnutt AN. Physiology of normal pregnancy. Crit Care Clin. 2004;20(4):609-15.

19. Sanders AB, Meislin HW, Ewy GA. The physiology of cardiopulmonary resuscitation. An update. JAMA. 1984;252(23):3283-6.

20. Chu J, Johnston TA, Geoghegan J, Royal College of O. Gynaecologists: maternal collapse in pregnancy and the puerperium: green-top guideline no. 56. BJOG. 2020;127(5):e14-52.

21. Kerr MG. The mechanical effects of the gravid uterus in late pregnancy. J Obstet Gynaecol Br Commonw. 1965;72:513-29.

22. Gabbott DA. Uterine displacement during CPR in the pregnant patient-why bother? Resuscitation. 2013;84(3):267-8.

23. Lavonas EJ, Drennan IR, Gabrielli A, Heffner AC, Hoyte CO, Orkin AM, et al. Part 10: special circumstances of resuscitation: 2015 American Heart Association guidelines update for cardiopulmonary resuscitation and emergency cardiovascular care. Circulation. 2015;132(18 Supplement12):S501-18.

24. Lott C, Truhlar A, Alfonzo A, Barelli A, Gonzalez-Salvado V, Hinkelbein J, et al. European resuscitation council guidelines 2021: cardiac arrest in special circumstances. Resuscitation. 2021;161:152-219.

25. Truhlar A, Deakin CD, Soar J, Khalifa GE, Alfonzo A, Bierens JJ, et al. European resuscitation council guidelines for resuscitation 2015: section 4. Cardiac arrest in special circumstances. Resuscitation. 2015:95:148-201.

26. Vanden Hoek TL, Morrison LJ, Shuster M, Donnino M, Sinz E, Lavonas EJ, et al. Part 12: cardiac arrest in special situations: 2010 American Heart Association Guidelines for cardiopulmonary resuscitation and emergency cardiovascular care. Circulation. 2010;122(18 Suppl 3):S829-61.

27. Neumar RW, Shuster M, Callaway CW, Gent LM, Atkins DL, Bhanji F, et al. Part 1: executive summary. Circulation. 2015;132(18_suppl_2):S315-67.

28. Moher D, Liberati A, Tetzlaff J, Altman DG, Group P. Preferred reporting items for systematic reviews and meta-analyses: the PRISMA statement. J Clin Epidemiol. 2009;62(10):1006-12.

29. Sterne JAC, Savovic J, Page MJ, Elbers RG, Blencowe NS, Boutron I, et al. RoB 2: a revised tool for assessing risk of bias in randomised trials. Bmj. 2019;366:14898.

30. Higgins JPT, Thomas J, Chandler J, Cumpston M, LiT, Page MJ, et al., editors. Cochrane handbook for systematic reviews of interventions. 2nd ed. Chichester: Wiley; 2019.

31. Borenstein M, Hedges LV, Higgins JPT, Rothstein H: Introduction to metaanalysis. Chichester:Wiley:; 2009.

32. Deeks JJ, Higgins JPT, Altman DG, on behalf of the Cochrane Statistical Methods Group. Analysing data and undertaking meta-analyses. In: Higgins JPT, Thomas J, Chandler J, Cumpston M, Li T, Page MJ, Welch VA, editors. Cochrane handbook for systematic reviews of interventions. 2nd ed. Chichester: Wiley; 2019.
33. Rücker G, Schwarzer G, Carpenter JR, Schumacher M. Undue reliance on 12 in assessing heterogeneity may mislead. BMC Med Res Methodol. 2008;8(1):79.

34. Borenstein M, Higgins JPT, Hedges LV, Rothstein HR. Basics of meta-analysis: 12 is not an absolute measure of heterogeneity. Res Synth Methods. 2017:8(1):5-18.

35. Borenstein M. Research Note: In a meta-analysis, the I(2) index does not tell us how much the effect size varies across studies. J Physiother. 2020;66(2):135-9.

36. Gamble C, Hollis S. Uncertainty method improved on best-worst case analysis in a binary meta-analysis. J Clin Epidemiol. 2005;58(6):579-88.

37. Higgins JP, White IR, Wood AM. Imputation methods for missing outcome data in meta-analysis of clinical trials. Clin Trials. 2008;5(3):225-39.

38. Guyatt GH, Oxman AD, Vist GE, Kunz R, Falck-Ytter Y, Alonso-Coello P, et al. GRADE: an emerging consensus on rating quality of evidence and strength of recommendations. BMJ. 2008;336(7650):924-6.

39. Schünemann HJ, Higgins JPT, Vist GE, Glasziou P, Skoetz EAAN, Guyatt GH, et al. Completing 'Summary of findings' tables and grading the certainty of the evidence. In: Higgins JPT, Thomas J, Chandler J, Cumpston M, Li T, Page MJ, Welch VA, editors. Cochrane handbook for systematic reviews of interventions. 2nd ed. Chichester: Wiley; 2019.

40. Lee JH, Choa M, Park JS, Kim S, Park YS, Chung SP. Comparative evaluation of chest compression in a 30degrees inclined lateral position designed for pregnant cardiac arrest patients-manikin study. J Korean Soc Emerg Med. 2011;22(6):650-5.

41. Kim S, You JS, Lee HS, Lee JH, Park YS, Chung SP, et al. Quality of chest compressions performed by inexperienced rescuers in simulated cardiac arrest associated with pregnancy. Resuscitation. 2013;84(1):98-102.

42. Komasawa N, Ueki R, Yamamoto N, Kaminoh Y, Tashiro C. Comparison of left-side and right-side approaches for chest compressions in the left-lateral tilt position: a manikin study of maternal cardiopulmonary resuscitation. Int J Obstet Anesth. 2013;22(4):354-5.

43. Butcher M, Ip J, Bushby D, Yentis SM. Efficacy of cardiopulmonary resuscitation in the supine position with manual displacement of the uterus vs lateral tilt using a firm wedge: a manikin study. Anaesthesia. 2014;69(8):868-71.

44. Dohi S, Ichizuka K, Matsuoka R, Seo K, Nagatsuka M, Sekizawa A. Coronary perfusion pressure and compression quality in maternal cardiopulmonary resuscitation in supine and left-lateral tilt positions: a prospective, crossover study using mannequins and swine models. Eur J Obstet Gynecol Reprod Biol. 2017;216:98-103.

45. Ip JK, Campbell JP, Bushby D, Yentis SM. Cardiopulmonary resuscitation in the pregnant patient: a manikin-based evaluation of methods for producing lateral tilt. Anaesthesia. 2013;68(7):694-9.

46. Goodwin AP, Pearce AJ. The human wedge. A manoeuvre to relieve aortocaval compression during resuscitation in late pregnancy. Anaesthesia. 1992;47(5):433-4.

47. Rees GA, Willis BA. Resuscitation in late pregnancy. Anaesthesia. 1988:43(5):347-9.

48. Panchal AR, Bartos JA, Cabanas JG, Donnino MW, Drennan IR, Hirsch KG, et al. Part 3: adult basic and advanced life support: 2020 American Heart Association guidelines for cardiopulmonary resuscitation and emergency cardiovascular care. Circulation. 2020;142(16_suppl_2):S366-468.

49. Mendonca C, Griffiths J, Ateleanu B, Collis RE. Hypotension following combined spinal-epidural anaesthesia for Caesarean section. Left lateral position vs. tilted supine position. Anaesthesia. 2003;58(5):428-31.

50. Cyna AM, Andrew M, Emmett RS, Middleton P, Simmons SW. Techniques for preventing hypotension during spinal anaesthesia for caesarean section. Cochrane Database Syst Rev. 2006;(4):CD002251.

51. Kwon OY. The changes in cardiopulmonary resuscitation guidelines: from 2000 to the present. J Exerc Rehabil. 2019;15(6):738-46.

52. Guidelines for cardiopulmonary resuscitation and emergency cardiac care. Emergency Cardiac Care Committee and Subcommittees, American Heart Association. Part III. Adult advanced cardiac life support. JAMA 1992, 268(16):2199-2241.

53. Kundra P, Khanna S, Habeebullah S, Ravishankar M. Manual displacement of the uterus during Caesarean section. Anaesthesia. 2007;62(5):460-5. 
54. Elbourne DR, Altman DG, Higgins JP, Curtin F, Worthington HV, Vail A. Meta-analyses involving cross-over trials: methodological issues. Int J Epidemiol. 2002;31(1):140-9.

55. Senn S. Cross-over trials in clinical research. 2nd ed. Chichester: Wiley; 2002.

56. Queensland Clinical Guidelines. Trauma in pregnancy. In.; 2019.

\section{Publisher's Note}

Springer Nature remains neutral with regard to jurisdictional claims in published maps and institutional affiliations.

- fast, convenient online submission

- thorough peer review by experienced researchers in your field

- rapid publication on acceptance

- support for research data, including large and complex data types

- gold Open Access which fosters wider collaboration and increased citations

- maximum visibility for your research: over 100M website views per year

At BMC, research is always in progress.

Learn more biomedcentral.com/submissions 